\title{
Development of a Microcompact Fuel-cell Vehicle Equipped with a Hydrogen Generator
}

\author{
Kenji Takahara $^{1}$ and Kouji Maekawa ${ }^{2}$ \\ ${ }^{1}$ Department of Electrical Engineering, Fukuoka Institute of Technology, takahara@fit.ac.jp \\ ${ }^{2}$ Department of Electrical and Electric Engineering, Kitakyushu National College of Technology, maekawa@apps.kct.ac.jp
}

\begin{abstract}
The purpose of this study is to develop a microcompact fuel-cell vehicle equipped with a hydrogen generation system. Hydrogen is generated by the reaction between water and activated aluminum particles without carbon dioxide emission. The activated aluminum is made of aluminum cutting waste through activation treatments such as compression crushing and freezing dry. One gram of the activated aluminum particles can generate about 1.1 liters of pure hydrogen. The developed hydrogen generator is consists of a water tank, an electrical pump, a reaction container, a condensate return tank, sensors and a one-chip microcomputer. It generated about 1-4 [l/min] of hydrogen over one hour. A microcompact vehicle was manufactured experimentally based on a delta trike. The front wheel was driven by a brushless motor of 100 [W]. The developed hydrogen generator and a fuel-cell of 100 [W] were equipped on the microcompact vehicle. It was confirmed that the vehicle drive at about 11 [km/h] over 90 minutes.
\end{abstract}

\section{Keywords}

hydrogen generation, activated aluminum particles, hydrogen generator, fuel-cell electric vehicle, threewheel

\section{INTRODUCTION}

The consumption energy of humanity has increased with the progress in science and technology. Most of such energy is produced from the combustion of fossil fuels. That has pumped carbon dioxide into the atmosphere and increased serious global environmental problems globally. Furthermore, because fossil fuel is used as resinous materials as well as an energy source its consumption must be reduced.

According to "The energy basic plan" reviewed in 2014, the necessity of the technology development towards the realization of low carbon society is emphasized [Ministry of Economy, Trade and Industry, 2014]. About twenty percent of $\mathrm{CO}_{2}$ in japan is emitted from transportation department. Against this background, it is desired to develop an electrical vehicle which has superior performance in energy and environmental design. And the car has to be compact to accommodate the future population decline and aged society.

It has gotten a lot of attention recently as an ecofriendly vehicle because a fuel-cell vehicle (FCV) does not discharge harmful gas [Tange, 2005; Hydrogen and Fuel Cell Handbook Editing Committee, 2006]. But it is thought to need a large cost and a lot of time for constructing the infrastructure including hydrogen station. Additionally, there is a problem in the safe deployment method of the high pressure hydrogen cylinder.

It is necessary to generate hydrogen by some methods, because it does not exist as resources naturally. The reforming of fossil fuel which is one of the methods for generating hydrogen is excellent in the economic efficiency. [Honma, 2003; Koseki, 2005; Iwabuchi, 2005; Satomi, 2005; Akamatsu, 2005] However, $\mathrm{CO}_{2}$ is generated in the process of that hydrogen production. That is, the reforming of fossil fuel is not a solution of the fundamental energy problems, because it is essentially identical to consumption of the petroleum, natural gas and so on.

Activated aluminum proposed by Watanabe et al. reacts with water to generate pure hydrogen [Watanabe, 2007; Watanabe et al., 2007]. After the reaction, it changes to oxidized aluminum which is environmentally-friendly. We have studied the control of hydrogen generation using the reaction between the activated aluminum particles and water and its applications. [Takahara et al., 2008a; 2008b; Maekawa et al., 2011; 2012]

The activated aluminum particles are able to be carried on safely, because they are stable substance. Therefore, it is considered that the activated aluminum particles are available as hydrogen source of a FCV. In this study, a hydrogen generator for a microcompact FCV is developed and is equipped on an experimental three-wheeled vehicle. Here, the activated aluminum and the developed hydrogen generator are described 
firstly. Secondary, the outline of our experimental delta trike is illustrated. The experiment is carried out to examine the performance of the microcompact FCV equipped with the hydrogen generator.

\section{MATERIALS AND METHODS}

\subsection{Activated aluminum particles and hydrogen gen- erator}

The activated aluminum particles are produced through the following processes.

- Shredded aluminum sawdust or atomized aluminum are compression-crushed to the size of a particle equal to or less than $20[\mu \mathrm{m}]$ by a special millstone in cold water.

- The aluminum particles compression-crushed are dried in vacuo under a certain pattern of temperature change.

These processes make many nao-cracks inside the microparticulated aluminum. $\mathrm{AlH}_{3}$ is produced around the tip of nano-crack and expand along the each crack by corrosion reaction [Markus, 1974]. In theory, one gram of the activated aluminum particles generates 1.35 [1] of pure hydrogen under the condition of $1 \mathrm{~atm}$ and 25 degree. It is confirmed that an average of 1.1 [1] of hydrogen is generated by $1[\mathrm{~g}]$ of the activated aluminum observationally.

The surface of the activated aluminum particles is coated with hydroxide film which indicates low probability of dust explosion. Therefore, it is conceivable to be useful as hydrogen source of a FCV because it is transferred and stored safely.

The hydrogen generating reaction exhibits the following characteristics.

- This hydrogen generating response is exothermic reaction.

- Because the reaction has temperature dependence it is accelerated with increase in temperature.

- The hydrogen generating reaction becomes active gradually and converges with decreasing the reactant.

- When hydrogen is generated briskly, it is difficult to stop the reaction.

That is, the quantity of hydrogen generation depends on quantity of water contacting with the activated aluminum directly and the reaction temperature. Therefore, it is considered that the reaction of hydrogen generation is controlled by regulating water supply to the activated aluminum.

In the next section, the developed hydrogen generator and its characteristic will be described.

\subsection{Hydrogen Generator}

Here, it is assumed that the experimental microcompact vehicle which a developed hydrogen generator is equipped with runs about one hour for neighborhood shopping. It is an eco-friendly hybrid vehicle that is driven by a FC and a lead battery. The capacity of the FC (Chemix FC-060-18) is chosen as 100 [W]. The hydrogen generator is designed to generate up to 4 [1/ $\mathrm{min}$ ] of hydrogen for over one hour.

The diagram of the hydrogen generator is shown in Figure 1. The system consists of a water tank, an electrical pump, a reaction container, a radiator, a water recycling tank, sensors and a one-chip microcomputer. A 450-grams-pack of the activated aluminum is put in the reaction container. Water is supplied form the water tank to the reaction container through the electrical pump driven the signals by the one-chip mi-

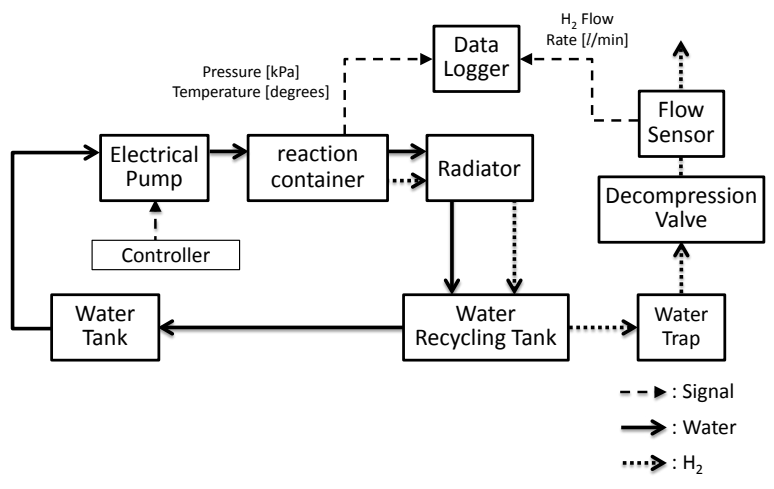

Fig. 1 Diagram of hydrogen generator



Fig. 2 Outer appearance of hydrogen generation system 
crocomputer. When the activated aluminum particles come into contact with water hydrogen is generated. Because the generated hydrogen is moisture-laden gas at high temperature it cooled through the radiator. The hydrogen is supplied to the FC after being dewatered through the water trap. In order to downsize the water tank, the water cooled by the radiator is recovered into the water recycling tank. Figure 2 shows the outer appearance of the hydrogen generation system.

The hydrogen generation characteristic when water is supplied in $30[\mathrm{ml} / \mathrm{min}]$ is shown in Figure 3. This result shows the developed system keeps hydrogen generation in $4.0[1 / \mathrm{min}]$ over one hour.

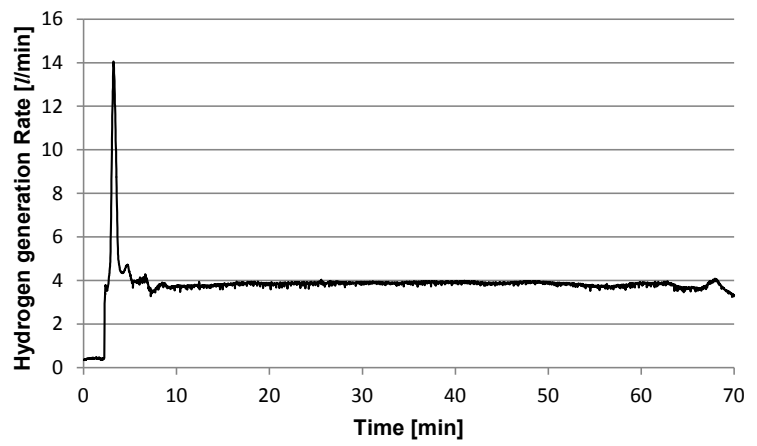

Fig. 3 Hydrogen generation rate at $30[\mathrm{ml} / \mathrm{min}]$ of the water supply

Next, the hydrogen generation characteristic at the different water flow rate was measured. Figure 4 illustrates that the flow rate of hydrogen is changed due to quantity of water flow. When the water flow rate is set in $25[\mathrm{ml} / \mathrm{min}]$ and $35[\mathrm{ml} / \mathrm{min}]$, the hydrogen flows in about $2.0[1 / \mathrm{min}]$ and $4.5[1 / \mathrm{min}]$, respectively. That means the hydrogen generation rate is determined by regulating flow rate of the water.

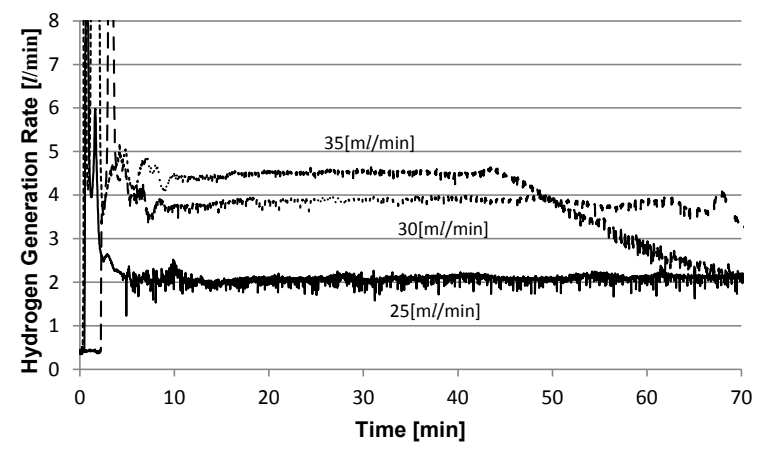

Fig. 4 Comparison of hydrogen generation characteristic at different water flow rate

Therefore, it is confirmed that the developed hydrogen generation system can be realized the assumed performance specifics.
In the next session, the developed hydrogen generation system will be implemented on a delta trike. The supply experiment of the hydrogen and driving test will be performed.

\section{EXPERIMENTS}

\subsection{Experimental three-wheeled vehicle}

The experimental three-wheeled vehicle is shown in Figure 5. It is a delta trike based on a trishaw. The front wheel is an in-wheel motor (M0124D-V, $24 \mathrm{~V}$, $100 \mathrm{~W}, \mathrm{MITSUBA})$. The hydrogen generator, a FC and control system are put on the rear carrier. The FC and two lead batteries are connected in parallel with the controller of the motor. The lead batteries are used to compensate for electrical power at the time of starting or at the time of driving up a slope.



Fuel Cell

Fig. 5 Experimental three-wheeled vehicle

Because the output voltage of the FC is changed according to its electrical output power, a boost DC-DC converter is connected between the $\mathrm{FC}$ and the lead batteries. The outline of the vehicle drive system is shown in Figure 6.



Fig. 6 Outline of the vehicle drive system

In the hydrogen system, the water pump (KNF FEM1.09 KPSM-2) is driven by external signals from a one-chip microcomputer (Arduino Uno). A pouch which four hundred fifty grams of the activated aluminum particles is packed in was set into the reaction container. Five gram of accelerator activator is mixed to the activated aluminum particles in order to boost hydrogen generation promptly after supplying water. The accelerator activator is made of sodium hydrox- 
ide, calcium carbonate and so on.

When water is supplied to the pouch of the activated aluminum particles, the temperature in the reaction container is raised by deliquescence of the accelerator activator. At the same time, hydrogen is generated by the reaction between water and the activated aluminum particles. Because the reaction container is held at high temperature, the hydrogen continues being generated. A safety valve attached to the reaction container works when the pressure is beyond a certain level.

Driving experiments were conducted in the parking of Fukuoka Institute of Technology. One lap of the driving course was about 105 [m]. Two lead batteries were charged up to $13.0[\mathrm{~V}]$ at the time of the experiment start, respectively. One liter of water was poured into the water tank.

Figure 7 shows a result of driving experiment. The velocity of the vehicle, the electric power of the FC, the electric power of the lead batteries, the total electric power, the pressure of the reaction container are illustrated in Figure 7 (a), (b), (c), (d) and (e), respectively. The pressure of the reaction container began to increase after approximately one minute of supplying water. After about two minutes, output from the FC increased. The experimental three-wheeled vehicle began to run approximately four minutes later.

When the vehicle stopped, the electric power from the

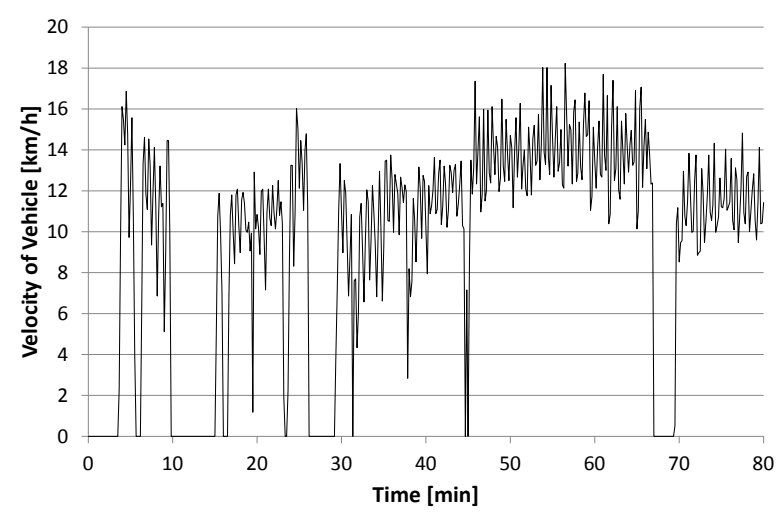

(a) Velocity of the vehicle

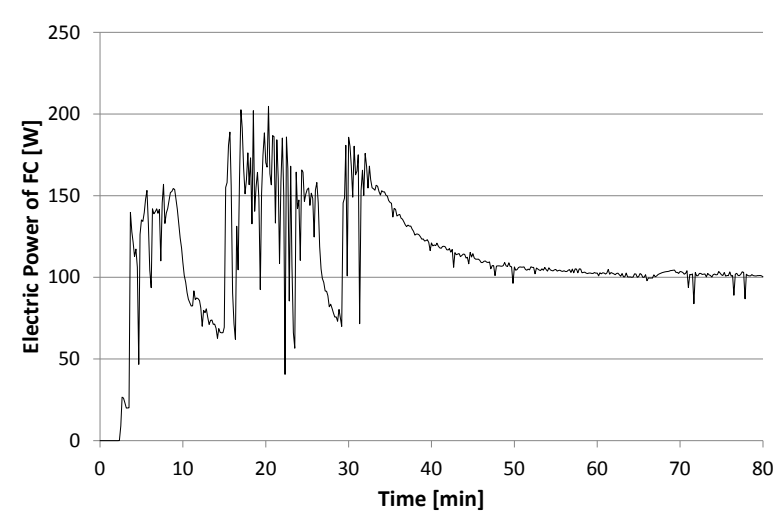

(b) Electric power of FC

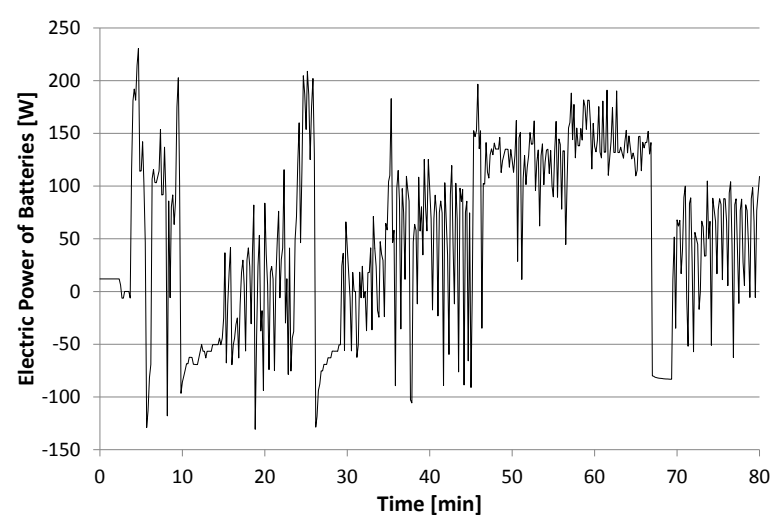

(c) Electric power of lead batteries

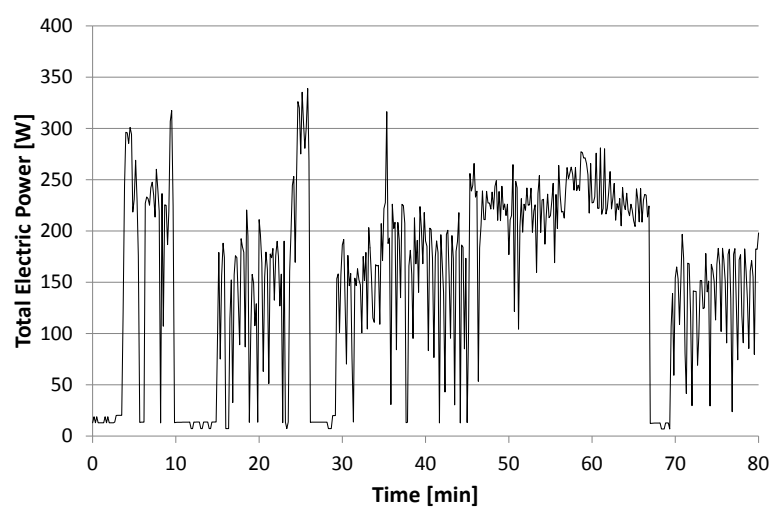

(d) Total electric power

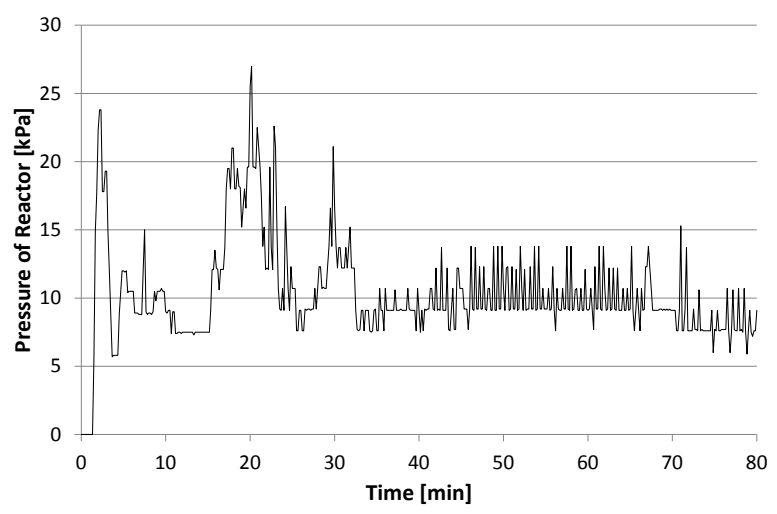

(e) Pressure of reaction container

Fig. 7 Result of driving experiment

FC was stored to the lead batteries. The FC and the lead batteries supplied electricity of approximately $100[\mathrm{~W}]$ and 50 [W] to the controller, respectively, at about $11[\mathrm{~km} / \mathrm{h}]$. After driving more than 60 [min], the pressure in the reaction container was kept at about 7 $[\mathrm{kPa}]$. Therefore, the result shows that hydrogen generating reaction continued. In this experiment, it was confirmed that the vehicle ran more than 90 minutes.

\section{CONCLUSIONS}

This study produced that the hydrogen generation system using water decomposition with the activated aluminum particles. The hydrogen generation system 
was applied to the experimental three-wheeled vehicle. The electric power from the FC was supplied to the controller of motor and the batteries depending on the situation. The vehicle was driven more than 90 minutes, and the hydrogen continued being generated after the vehicle stopped. Therefore, it is considered that the produced vehicle is useful to run for shopping near home about an hour.

The activated aluminum particles are stable substance as above mentioned. Therefore, if the activated aluminum particles expose to air in an accident, they are only oxidized slowly, and there is not the fear of dust explosion such as pure aluminum. Furthermore, even if the pure water for reactions spills, there is not the risk like strong acid and a strong alkaline solution. Hence, even in the case of the accident, the developed microcompact FCV is not thought to cause heavy damage around.

Here, the hydrogen was generated at a certain constant rate. The hydrogen generation rate changes according to the supply of water. The construction of a system to control the hydrogen generation is an issue in the future

\section{Acknowledgment}

This study was partially supported by JSPS KAKENHI (Grants-in-Aid for Scientific Research (C) 24560559). We are grateful for their support.

\section{References}

Akamatsu, H., Infrastructure refinement for hydrogen society, The Journal of the Institute of Electrical Engineering of Japan, Vol. 125, No. 6, 352-355, 2005.

Honma, T., Illustration All of the Fuel Cell, Kohgyochohsakai, 2003.

Hydrogen and Fuel Cell Handbook Editing Committee, Hydrogen and Fuel Cell Handbook. Ohm-sha, 2006.

Iwabuchi, H., The review of hydrogen energy road map of Japan, USA and EU., The Journal of the Institute of Electrical Engineering of Japan, Vol. 125, No. 6, 340-343, 2005.

Koseki, K., Role of hydrogen in energy supply and policy for hydrogen economy in US, EU and Japan., The Journal of the Institute of Electrical Engineering of Japan, Vol. 125, No. 6, 336-339, 2005.

Maekawa, K., K. Takahara, T. Kajiwara, and M. Watanabe, Control of hydrogen generation from water molecules dissociated by activated aluminum particles based on fuzzy logic, Transactions of the Society of Instrument and Control Engineers, 2011.

Maekawa, K., K. Takahara, and T. Kajiwara, A portable fuel cell system using activated aluminum,
IEEJ Transactions on Industry Applications, Vol. 132, No. 10, 997-1002, 2012.

Markus, O. S., Hydrogen in metals, I. M. Bernstein (eds.) ASM International, 1974.

Ministry of Economy, Trade and Industry, The energy basic plan, http://www.meti.go.jp/pre ss/2014/04/20140411001/20140411001-1.pdf, 2014.

Satomi, T., Review of RD\&D status on polymer electrolyte fuel cell for stationery application in Japan., The Journal of the Institute of Electrical Engineering of Japan, Vol. 125, No. 6, 348-351, 2005.

Tange, S., World activities on fuel cell vehicle development and demonstration, The Journal of the Institute of Electrical Engineering of Japan, Vol. 125, No. 6, 344-347, 2005.

Takahara, K., K. Maekawa, T. Kajiwara, K. Ohyama, M. Watanabe, Y. Yamanouchi, and H. Kawaguchi, Measurements of hydrogen generation characteristics using activated aluminum particles. The 2007 annual meeting record IEE Japan, Vol. 7, No. 108, 2007.

Takahara, K., K. Maekawa, T. Kajiwara, and M. Watanabe, Identification of hydrogen generation characteristics from activated aluminum particles using ARMA model on the assumption of the applications for fuel-cell electric vehicle, Journal of Asian Electric Vehicle, Vol. 6, No. 2, 1153-1157, 2008.

Watanabe, M., Concept of three dimensional reactions: Hydrogen generation by dissociating water molecular in aluminum particles and an application to handy mobile type $\mathrm{H}_{2}$ generators, Fuel Cell., Vol. 7, No. 1, 52-56, 2007.

Watanabe, M. and K. Takahara, Generation of pure hydrogen from water using activated aluminum powder, Proceedings of Joint Seminar on Environmental Science and Disaster Mitigation Research 2007, 15-16, 2007.

(Received September 9, 2014; accepted September 29, 2014) 